\title{
Solidification of Immiscible Alloys under High Magnetic Field: A Review
}

\author{
Chen Wei ${ }^{1}$, Jun Wang ${ }^{1, *}$, Yixuan $\mathrm{He}^{1}$, Jinshan $\mathrm{Li}^{1, *}$ and Eric Beaugnon ${ }^{2}$ \\ 1 State Key Laboratory of Solidification Processing, Northwestern Polytechnical University, \\ Xi'an 710072, China; 18229022561@163.com (C.W.); yixuanhenwpu@126.com (Y.H.) \\ 2 INSA Toulouse, University Grenoble Alpes, University Toulouse Paul Sabatier, EMFL, CNRS, LNCMI, \\ 38000 Grenoble, France; eric.beaugnon@lncmi.cnrs.fr \\ * Correspondence: nwpuwj@nwpu.edu.cn (J.W.); ljsh@nwpu.edu.cn (J.L.)
}

check for updates

Citation: Wei, C.; Wang, J.; He, Y.; Li, J.; Beaugnon, E. Solidification of Immiscible Alloys under High Magnetic Field: A Review. Metals 2021, 11, 525. https://doi.org/ $10.3390 /$ met11030525

Academic Editors: Gunter Gerbeth and Imre Bakonyi

Received: 27 January 2021

Accepted: 19 March 2021

Published: 23 March 2021

Publisher's Note: MDPI stays neutral with regard to jurisdictional claims in published maps and institutional affiliations.

Copyright: (c) 2021 by the authors. Licensee MDPI, Basel, Switzerland. This article is an open access article distributed under the terms and conditions of the Creative Commons Attribution (CC BY) license (https:// creativecommons.org/licenses/by/ $4.0 /)$.

\begin{abstract}
Immiscible alloy is a kind of functional metal material with broad application prospects in industry and electronic fields, which has aroused extensive attention in recent decades. In the solidification process of metallic material processing, various attractive phenomena can be realized by applying a high magnetic field (HMF), including the nucleation and growth of alloys and microstructure evolution, etc. The selectivity provided by Lorentz force, thermoelectric magnetic force, and magnetic force or a combination of magnetic field effects can effectively control the solidification process of the melt. Recent advances in the understanding of the development of immiscible alloys in the solidification microstructure induced by HMF are reviewed. In this review, the immiscible alloy systems are introduced and inspected, with the main focus on the relationship between the migration behavior of the phase and evolution of the solidification microstructure under HMF. Special attention is paid to the mechanism of microstructure evolution caused by the magnetic field and its influence on performance. The ability of HMF to overcome microstructural heterogeneity in the solidification process provides freedom to design and modify new functional immiscible materials with desired physical properties. This review aims to offer an overview of the latest progress in HMF processing of immiscible alloys.
\end{abstract}

Keywords: high magnetic field; immiscible alloy; solidification; phase separation; microstructure

\section{Introduction}

Immiscible alloy is characterized by the miscibility gap in the phase diagram, which generally experiences liquid-liquid phase separation (LLPS) in this zone [1], as shown in Figure 1. Many of them have a wide range of applications, such as superconducting, electrical contact, and self-lubricating materials [2-7]. In particular, immiscible alloy with a regular core-shell structure has huge application potential in electronic packaging solders [8,9]. However, when a single-phase liquid is cooled into the miscibility gap, the homogeneous liquid will be separated into two liquids with diverse properties and compositions, and then the Marangoni and Stokes motions of the droplets lead to the formation of phase-segregated microstructure of immiscible alloy $[10,11]$. The control of microstructure formation during the solidification of immiscible alloy is becoming increasingly important for various scientific and technical applications, because a close relationship exists between the properties of a material and it microstructure.

In recent years, an important new technique called high magnetic field (HMF) processing has been applied to material processing as a non-contact method [12-14], especially during solidification $[15,16]$, which contributes to the influencing of secondary particle migration/orientation [17] and liquid metal motion and convection [18,19] to achieve more accurate control over the microstructure of materials [20,21]. The development of superconductivity technology has made it easy to obtain HMF of $10 \mathrm{~T}$ and above, which has promoted the application of HMFs in materials science and engineering and is therefore 
regarded as a new opportunity in this field [22,23]. It is difficult to define a critical value of a magnetic field to express "high". Therefore, it is usually determined based on pragmatic correspondence of the magnetic response of the investigated material. When the response of the external magnetic field is large enough to affect the characteristics of a material, such as melt convection, mass transfer, or motion behavior, the magnetic field can be considered as an HMF of the material. If not, the contrary, the field is weak [24].

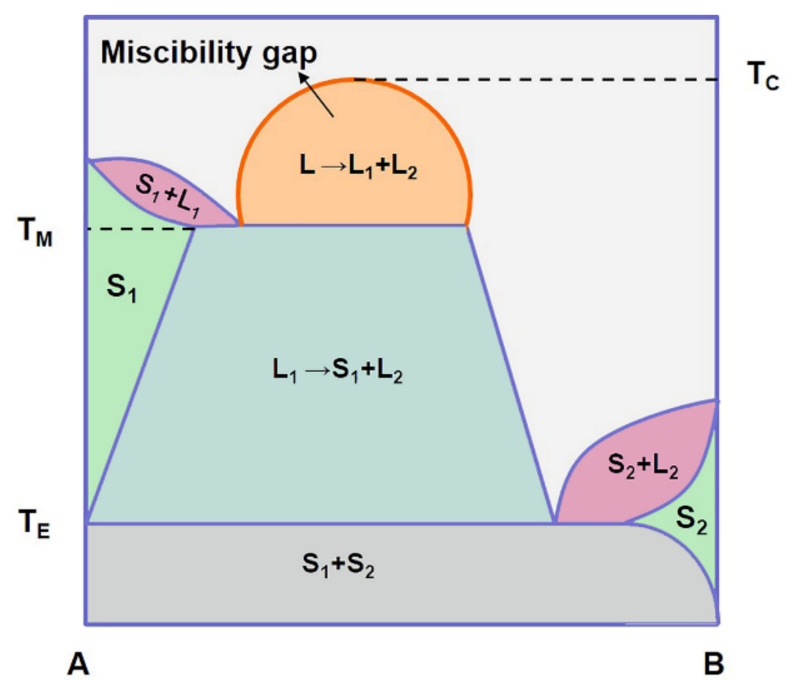

Figure 1. Schematic phase diagram of immiscible alloy in the liquid state.

In the process of solidification, it has been discovered that the microstructure and properties of alloys are closely dependent on the phase migration behavior and distribution $[25,26]$. Therefore, a comprehensive understanding of the evolution of phase migration behavior under HMF is of great significance for predicting and controlling the final microstructure and properties of materials. At present, many researchers have studied the effects of HMF on the migration and distribution of the phase during the solidification process of immiscible alloy. The results showed that the migration of phase under HMF exhibited divergent behaviors compared with normal conditions [27-30].

In general, under HMF conditions, the microstructure of immiscible alloy is modified on account of the Lorentz force, magnetic forces, thermoelectric magnetic force $\left(\mathrm{F}_{\mathrm{TEMF}}\right)$, magnetic dipole-dipole interactions, and magnetic torque. However, there are three main forces that play a leading role in the magnetic field. The Lorentz force is stimulated through the interaction of the applied magnetic field and the electric current. In any material, if there is an interface with a temperature gradient, then an thermoelectric current will be generated in a closed loop based on the Seebeck effect [31], and thus $\mathrm{F}_{\text {TEMF }}$ will be produced by the interaction between the current and the imposed magnetic field. Supposing that there is a magnetic field gradient, the magnetic force will be generated by the interaction between the applied magnetic field gradient and the magnetization of the material [32]. In these cases, a segregation or separation of diverse phases may be expected. In addition, in the past decade, the HMF in the treatment of immiscible metal materials has been one of the research hotspots in the field of materials engineering. The results show that the combination of the newly developed HMF technology and the classical laboratory research seems to be able to solve the phase separation, microstructure evolution, and performance problems of immiscible alloy in the cooling process of the liquid miscibility gap.

This paper was undertaken with the purpose of offering an insight into the evolution of phase migration and distribution in immiscible liquids in HMF, with an emphasis on understanding the synergism between the solidification microstructure and HMF. 


\section{The Solidification Process of Immiscible Alloy}

When the uniform immiscible alloy melt is cooled into the miscibility gap of the component, the evolution of the microstructure in liquid-liquid phase transformation is the result of the interaction of droplet nucleation, diffusion growth/coarsening [33,34], spatial migration and the resulting collision and coagulation and two-phase separation $[35,36]$. The solidification pathways in immiscible $\mathrm{Cu}-\mathrm{Co}$ alloy with different undercoolings were systematically expounded by Wei at al. [37], as shown in Figure 2. For the undercooling above the metastable miscibility gap, the solidification of the immiscible alloy commenced in a normal way, accompanied by nucleation and growth of the primary $\alpha$-Co dendrites. When the undercooling is lower than the metastable miscibility gap, primary LLPS, and even secondary LLPS will take place.

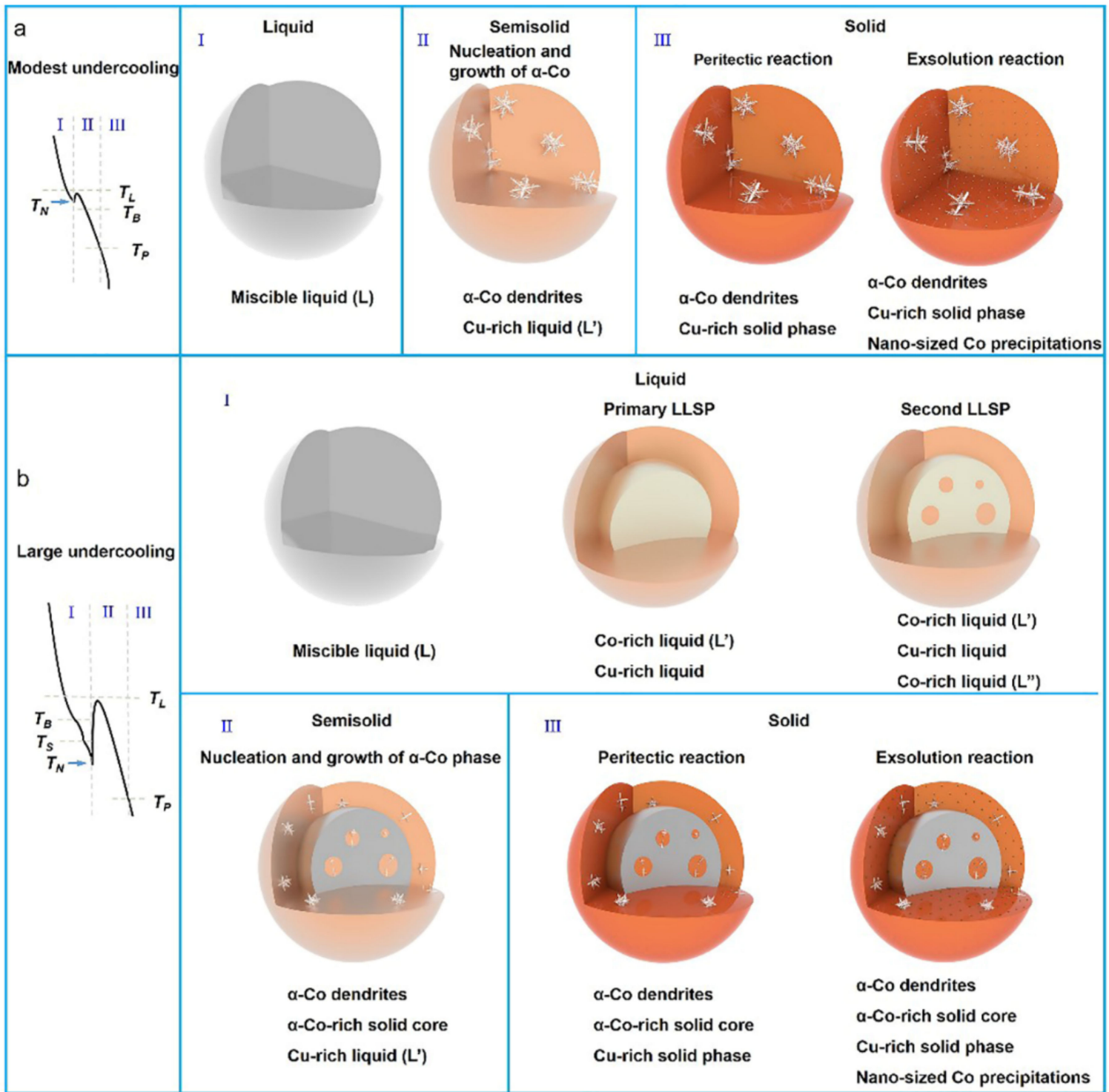

Figure 2. Schematic microstructural evolution of solidified $\mathrm{Cu}-\mathrm{Co}$ alloy at two different undercooling ranges. (a) Modest undercooling, i.e., TN is above the TB1, the liquid miscibility gap for the primary liquid-liquid phase separation (LLPS). (b) Large undercooling, i.e., TN, is below the TB2, the liquid miscibility gap of the separated Co-rich droplet formed via the primary LLPS [37].

At present, it is generally believed that the formation process of microstructures in immiscible alloy undergoes the following process (Figure 3): first, after the LLPS of immiscible alloy, the second phase droplets are first precipitated from the liquid matrix phase though the 
mechanism of spinodal decomposition or nucleation-growth. Second, then it is decomposed into two phases gradually from the outside and the inside, in which the liquid phase with small surface energy is easy to spread on the surface. Then third, the second phase droplet experiences a series of processes such as growth, condensation, collision, coagulation, and so on. Fourth, when the droplet grows to a certain size, under the action of Marangoni convection created by a temperature gradient inside the alloy and Stokes movement caused by the density difference, the second phase droplet migrates to the high temperature region of the alloy, namely the geometric center, and forms the core, and eventually forms the core-shell microstructure type or other types of segregation microstructures.

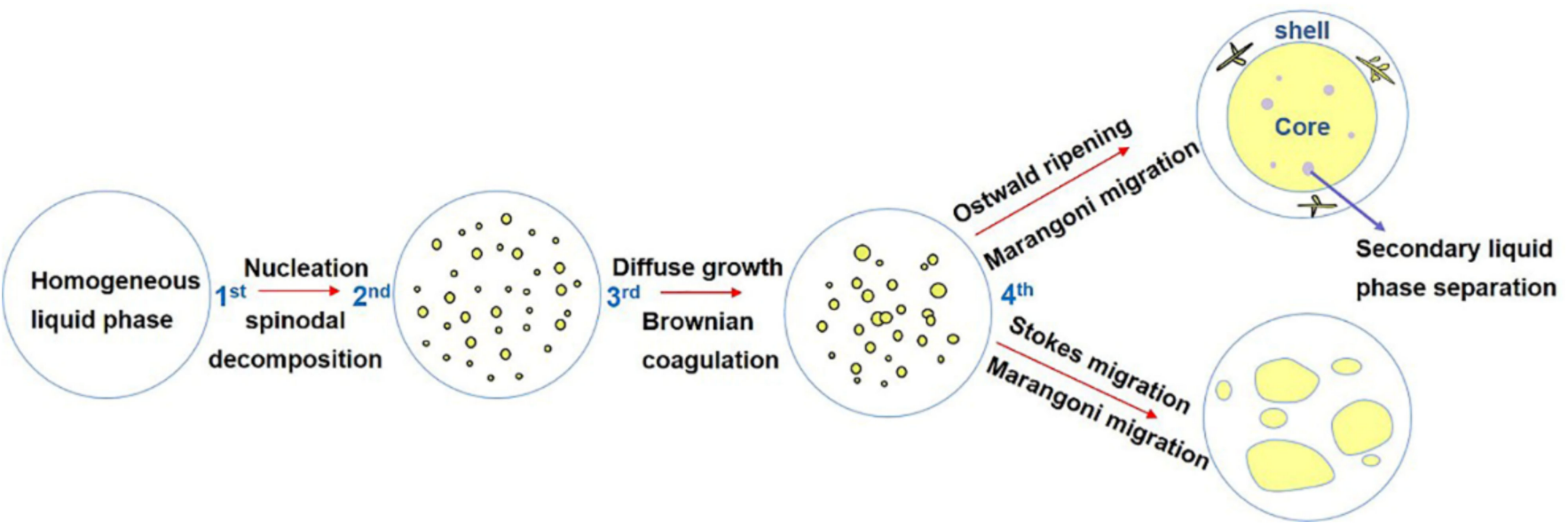

Figure 3. Schematic diagram of liquid-liquid phase separation process of immiscible alloy.

Considerable attempts have been made to simulate the microstructure evolution of immiscible alloy during liquid-liquid transformation by using diverse modeling approaches [38]. Liu et al. [39-41] established the phase field model of self-organized core-shell and core-shell-corona microstructures to investigate the formation mechanism. The simulation results showed that all the concurrent processes, containing spinodal decomposition, droplet drifting, surface wetting, collision, coagulation, and Marangoni motion, play a crucial role in the formation of core-shell and core-shell-corona microstructures.

\section{The Effect of HMF on the Formation Process of Microstructures}

\subsection{Basic Role of HMF in Material Processing}

For various forces and magnetic effects caused by $\mathrm{HMF}$, the origin of these effects is briefly introduced.

\subsubsection{The Lorentz Force}

The magnetic field line cut by the flowing melt generates the electric potential. Since both the liquid and solid metals are excellent conductors, the induced current $J_{u}$ generated in the liquid metal is expressed as

$$
J_{u}=\sigma_{L}(u \times B)
$$

where $\sigma_{L}$ is the conductivity of the liquid metal, $u$ is the velocity of the fluid, and $B$ is the strength of external magnetic field.

Under the condition of a magnetic field, the interaction between the magnetic field and the induced current produces the Lorentz force, the direction of which is always opposite to that of melt flow. The Lorentz force can be expressed as

$$
F_{L}=\sigma_{L}(u \times B) \times B
$$




\subsubsection{Thermoelectric Magnetic Force}

If the liquid-solid interface is located in magnetic field that is not parallel to the temperature gradient, $\mathrm{F}_{\mathrm{TEMF}}$ will occur naturally. Note that the above description is only feasible if the thermal gradient along the solid-liquid interface has a non-zero component. In an immiscible system, the $\mathrm{F}_{\mathrm{TEMF}}$ can be described as [27]

$$
F_{T E M F}=\frac{\sigma_{s} \sigma_{L} f_{s}}{\sigma_{s} f_{s}+\sigma_{L} f_{L}}\left(S_{s}-S_{L}\right) \nabla T \times B \times V_{1}
$$

where $f_{S}$ and $f_{L}$ are the solid and liquid fractions, respectively. $S_{S}$ and $S_{L}$ are the absolute thermoelectric power of solid phase and liquid phase, respectively. $\sigma_{S}$ is the electrical conductivities of $S_{L}$, and $\sigma_{L}$ is the electrical conductivities of $L_{1}$ matrix phase. $V_{1}$ represents the volume fraction of the solid.

\subsubsection{Magnetic Force}

When a material is magnetized in the magnetic field, the magnetic force will be produced by the combination of the magnetic field gradient [42]. In the actual situation, the longitudinal gradient magnetic field is generally used. According to the magnetic susceptibility of materials, the magnetic force is imposed in the direction of gravity or the opposite direction of gravity. The force on the $z$-axis component is given by [32]

$$
\mathrm{F}=V\left(\frac{1}{\mu_{0}}\right) \chi B \frac{d_{B}}{d_{Z}}
$$

where $V, \mu_{0}, \chi$, and $B$ respectively denote the volume of the material, the vacuum permeability, the magnetic susceptibility per unit volume, and the flux density along the $\mathrm{Z}$ direction.

If this simple description can be extrapolated to a binary system composed of the liquid matrix $M$ and distributed particles $P$ with different magnetic susceptibility, taken into account the buoyancy effect, the force can be expressed as [43]:

$$
F_{P}=V_{P}\left(\chi_{P}-\chi_{M}\right) \frac{1}{\mu_{0}} B \frac{d_{B}}{d_{Z}}-\left(\rho_{P}-\rho_{M}\right) V_{P} \mathrm{~g}
$$

where $\rho$ and g are the density and the gravitational acceleration, respectively. Assuming that the absolute susceptibility of $P$ is greater than that of $M$, and the value of $B \frac{d_{B}}{d_{Z}}$ is large enough, then $M$ is inclined to migrate in the matrix along the magnetic force direction (positive susceptibility) or in the opposite direction (negative susceptibility).

\subsubsection{Magnetic Dipole-Dipole Interaction}

If magnetic particles are placed in the magnetic field, these particles will become magnetic dipoles as a result of being magnetized. Dipole-dipole interaction is the mutual attraction of particles in a plane parallel to the direction of the magnetic field and the mutual repulsion of particles in a plane perpendicular to the magnetic field. It is assumed that the particles are approximately spherical, so the interaction energy is generated between two adjacent magnetic dipoles, $m_{1}$ and $m_{2}$, which can be given by [44],

$$
U_{M=} \frac{\mu_{0}}{4 \pi} \frac{l^{2} q_{m 1} q_{m 2}-3\left(q_{m 1} \cdot l\right)\left(q_{m 2} \cdot l\right)}{l^{5}}
$$

where the magnetic dipoles moments corresponding to $m_{1}$ and $m_{2}$ magnetic dipoles are $q_{m 1}$ and $q_{m 2}$, respectively, and $l$ represents the distance between the center of $m_{1}$ and $m_{2}$ particles. 
If the particle is paramagnetic, the resulting magnetic dipole moment is described using the follow formula:

$$
q_{m}=\frac{\pi r_{p}{ }^{3} \mu_{0} \chi_{e} H_{e X}}{6}
$$

where $r_{p}, \chi_{e}$, and $H_{e X}$, respectively denote the particle radius, the effective susceptibility of the particle, and the intensity of the applied magnetic field.

\subsubsection{Magnetic Torque}

The magnetic torque can be taken into account in two different cases, i.e., a ferromagnetic crystal in a uniform field and non-magnetic materials, for instance, diamagnetic and paramagnetic materials.

For the ferromagnetic crystal, the magnetization of the ellipsoidal is even and invariably parallel to the direction of the internal magnetic field. The magnetic torque can be expressed analytically as [45]

$$
\mathrm{T}=\mu_{0} H_{a} M V \sin \alpha
$$

where $\mu_{0}$ is the vacuum magnetic permeability constant, $V$ is the volume of the primary crystal, $\alpha$ is the angle between $M$ and $H_{a}, M$ is the magnetization, and $H_{a}$ is the applied magnetic field.

When diamagnetic and paramagnetic materials are magnetized via the magnetic field, materials will be impacted via the magnetic torque, since the magnetization vector and the magnetic field vector are not parallel. The magnetic torque in $Z$ direction can be given by [46]

$$
\mathrm{L}=\frac{V\left(\chi_{1}-\chi_{2}\right) B^{2} \sin 2 \theta}{2 \mu_{0}}
$$

where $\chi_{1}$ (along the $\mathrm{x}$ axis) and $\chi_{2}$ (along the $\mathrm{y}$ axis) represent the magnetic susceptibilities in the easily magnetized axis and the not easily magnetized axis, respectively. $\theta$ is the angle between the easily magnetized axis and the direction of the applied magnetic field.

\subsubsection{Magnetostatic Energy}

No matter what kind of magnetic medium is placed in the external magnetic field, it will be magnetized, so it will have certain magnetostatic energy. The magnetostatic energy $E_{m}$ per unit volume can be expressed as [47]

$$
E_{m}=\int_{0}^{H_{e x}} \mu_{0} M d H_{e f f}
$$

where $\mu_{0}$ is the vacuum magnetic permeability constant, $M$ is the magnetization, and $H_{e x}$ is the applied magnetic field.

From the point of a view of controlling the formation of a microstructure during solidification, due to the special effects of the HMF, a large number of researches have shown that the HMF can significantly affect the nucleation behavior, growth behavior, and coarsening and coagulation processes of immiscible alloy during solidification (see Figure 4).

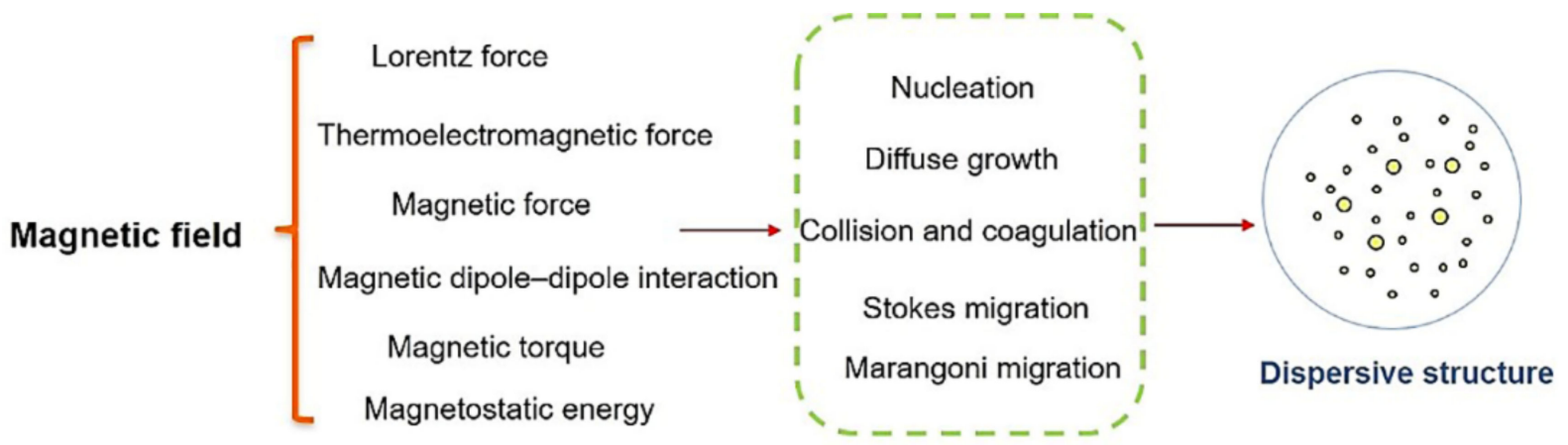

Figure 4. Schematic diagram of the mechanism of high magnetic field (HMF) effects during the solidification process. 


\subsection{HMF Effects on Nucleation of Immiscible Alloy}

In the condition of rapid solidification, the formation of microstructures of immiscible alloy is mainly dominated by the nucleation of the minority phase droplets. The results of previous researches have offered an important description of the variation in nucleation during the solidification process induced by HMF. At present, for different alloy systems, the nucleation mechanism under HMF is different. Undercooling is an important parameter for nucleation characterization. The application of the magnetic field may increase or decrease the maximum undercooling of alloy systems. Most alloys are nonferromagnetic at solidification temperature, and the solidification undercooling under HMF can be expressed as [48]

$$
\Delta \mathrm{T}=\frac{\Delta X^{s-L} B^{2}}{2 \mu_{0} \Delta H_{m}} T_{m}
$$

where $\Delta X^{S-L}$ is the magnetic susceptibility difference between liquid and solid phases, $B$ is the magnetic induction intensity of the external magnetic field, $\Delta H_{m}$ is the latent heat of metal solidification, and $T_{m}$ is the solidification temperature of metal without a magnetic field.

The volume susceptibility of metal at solidification temperature is usually between $10^{-4}$ and $10^{-7}$. If the magnetic susceptibility difference between liquid and solid phases is $10^{-4}$, the latent heat of metal solidification is $10^{7} \mathrm{~J} / \mathrm{m}^{3}$, the vacuum magnetic permeability is $4 \pi \times 10^{-7}$, the magnetic induction intensity of external magnetic field is $10 \mathrm{~T}$, and the solidification temperature of metal without magnetic field is $10^{3} \mathrm{~K}$, then the $\Delta \mathrm{T}$ is evaluated from Equation (1) as:

$$
\Delta \mathrm{T} \approx 0.1 \mathrm{~K}
$$

Therefore, during the solidification process of weak magnetic materials, the influence of $10 \mathrm{~T}$ magnetic field on the solidification point is small. However, for magnetic alloys, the effect of HMF is more significant [49,50]. The nucleation behavior of $\mathrm{Ni}-90 \mathrm{at} \% \mathrm{Cu}$ alloys in HMF was investigated by Liu [51]. The undercooling of the alloy increased significantly before nucleation in the HMF of $11.5 \mathrm{~T}$ (Figure 5a). The increase of undercooling under HMF was ascribed to the inhibition of melt convection by Lorentz forces, which could delay the formation of oxides required for heterogeneous nucleation. However, Wei et al. [52] found that the application of HMF would increase the nucleation temperature, resulting in a decrease in the undercooling (see Figure 5b). For magnetic material, during the non-equilibrium solidification, HMF has a great influence on the solidification point. The relation between solidification point temperature and applied HMF is given by [48].

$$
T_{2}-T_{1} \approx \frac{2 \mu_{0} M_{S} H_{e x}}{\left(S_{A}^{\beta}-S_{A}^{\alpha}\right)+\left(S_{A}^{\beta}-S_{A}^{L}\right)+R \ln \frac{\left(a_{A}^{\beta}\right)^{2}}{a_{A}^{\alpha} a_{A}^{L}}}
$$
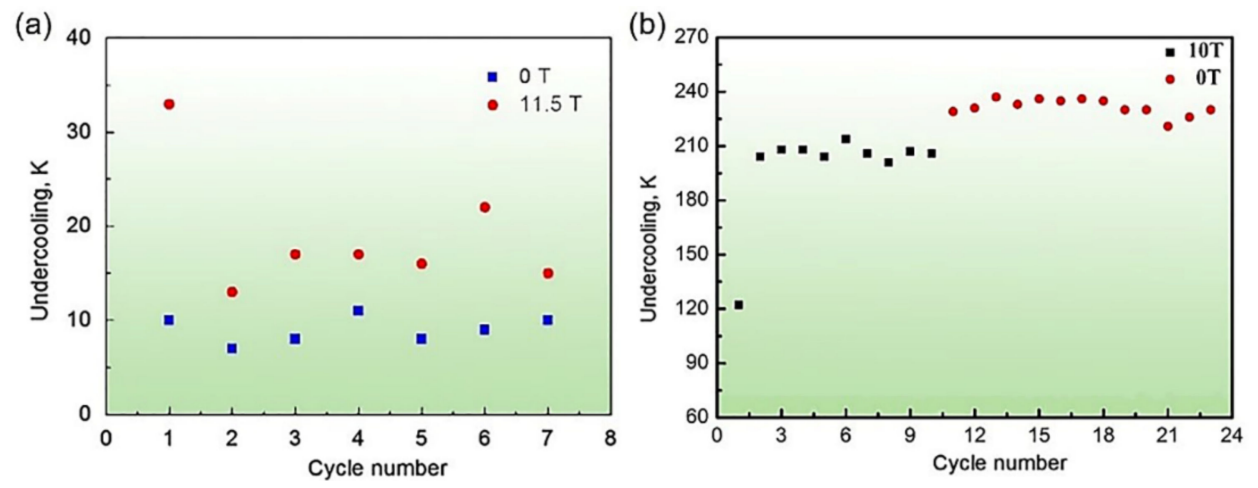

Figure 5. (a) The distribution of undercooling as a function of cycle number without and with HMF of $11.5 \mathrm{~T}$ [51]; (b) undercooling of $\mathrm{Cu}_{66.67} \mathrm{Co}_{33.33}$ alloy at different cycle numbers with and without HMF of $10 \mathrm{~T}$ [52]. 
Without HMF, the phase temperature changes to $T_{1}$. With the magnetic field, the transformation temperature of phase changes to $T_{2}$, where $H_{e x}$ is the applied magnetic field, $M$ is the magnetic moment that saturates at magnetic intensity, $S$ is the entropy, and subscript $A$ represents component $A$; the subscripts $\beta, \alpha$, and $L$ indicate solid Co-rich phase, liquid Corich phase, and liquid $\mathrm{Cu}$-rich matrix, respectively. The resulting equation shows that there is a certain relationship between the change of the magnetic field and transformation temperature. It can be seen from the equation that the change in transformation temperature is proportional to the $H_{e x}$. Under the action of the HMF, the nucleation temperature increases, meaning that the undercooling will decrease to some extent. Furthermore, Bian et al. [53] found that with the increase of HMF intensity, the binodal temperature of the immiscible alloys obviously moved to a higher temperature, which hindered the occurrence of alloy phase separation.

Based on the current analysis, there is no definite conclusion on the influence of HMF on the nucleation of different types of immiscible alloy systems, and no direct proof means is available, which needs to be further studied.

\subsection{HMF Effects on Growth of Immiscible Alloy}

The minority phase droplets nucleated in the supersaturated matrix grow up through solute atom diffusion in the matrix. On the other hand, when the droplets move in the growth process, the solute can also migrate via the convective flow. It can be considered that the growth of the droplets is governed through the convective diffusion solute transport. Recently, great efforts have been made to study the influence of HMF on solute diffusion growth of immiscible alloys.

Wang et al. [54] and Li et al. [55,56] studied the interdiffusion behavior of diverse solid/liquid interdiffusion couples under HMF, which indicated that a competition existed between the increase of $\mathrm{F}_{\mathrm{TEMF}}$ and the decrease of Lorentz force with the change of solid/liquid system. In general, the decrease of diffusion of liquid metal via magnetic field is mainly due to the suppression of convection, which leads to additional mass transfer. Botton et al. [57] predicted that a magnetic field of about $2.5 \mathrm{~T}$ would be sufficient to inhibit the diffusion of liquid metal to a degree comparable to microgravity measurements. Li et al. [58] characterized the solute diffusion behavior under HMF and found out that it strikingly depends on the magnetic flux density. Mathiak and Frohberg [59] performed the diffusion experiment for an In-Sn liquid system via the capillary method in various HMFs. The experimental results showed that the magnetic field can inhibit the diffusion of horizontal capillaries, but has little influence on the diffusion of vertical capillaries. Miyake et al. [60] used the same method to further investigate the temperature dependence of interdiffusion coefficient for In-Sn alloy without and with the $4 \mathrm{~T}$ magnetic field. Their experimental results demonstrated the reduction of diffusion under an imposed HMF. Zn-7wt.\%Bi immiscible alloy was in situ quenched at different HMFs. When the dimensions of Bi-rich particles are less than $1 \mu \mathrm{m}$, it can be considered that the particles grow only by diffusion. The decrease in the dimensions indicated that HMF inhibited the diffusion and growth of minority phase particles. However, the influence of HMF on the mobility of atoms in liquid metal is very weak [61]. Since diffusional growth occurs in the liquid state, the thermal motion of atoms is intense at this high temperature, and researchers believe that even an $18 \mathrm{~T} \mathrm{HMF}$ cannot significantly decrease the diffusion growth rate of minority phase elements [62]. It was found that different experimental methods combined with different HMFs have diverse influences on the diffusion growth of immiscible alloys.

\subsection{HMF Effects on Coarsening and Coagulation Process of Immiscible Alloy}

In a final stage of the liquid-liquid phase transformation, the dispersed minority droplets will coarsen and coagulate [63]. If two droplets collide directly, the hydrodynamic flow field generated by the collision will push the movement of neighboring droplets, resulting in more collision and coalescence events [39]. Therefore, the existence of melt flow significantly accelerates the coagulation of droplets. Some experiments have confirmed 
the remarkable influence of HMF on the melt flow. From the viewpoint of the inhibition of Lorentz force on the melt flow, it was found that coarsening and coagulation processes of droplets are obviously altered. For example, to characterize the solidification processes for $\mathrm{Cu}-\mathrm{Pb}$ immiscible alloy, the Lorentz force acts like a breaking force to prevent particles from colliding and coalescing. Apparently, the application of HMF reduces the coalescence rate of droplets, thus reducing the macrosegregation [64]. Yasuda et al. [65] performed directional solidification of an Al-In hypermonotectic alloy with HMF. As shown in Figure 6 , the Lorentz force produced by the applied magnetic field and eddy current brakes the horizontal melt flow, thus suppressing the movement of the In-rich droplets and enhancing the engulfment of In-rich droplets by the Al-rich matrix. In addition, the effect of HMF on the flow of conductive melt can be measured by the great change of Hartmann number and the change of apparent viscosity. The Hartmann number can be expressed as [66]

$$
H_{a}=B L\left[\frac{\sigma_{M}}{\eta_{M}}\right]^{\frac{1}{2}}
$$

where $B$ is the magnetic induction strength, $L$ is the characteristic size defined as the diameter of second phase droplets, $\eta_{M}$ is the matrix viscosity, and $\sigma_{M}$ is the conductivity of the matrix.

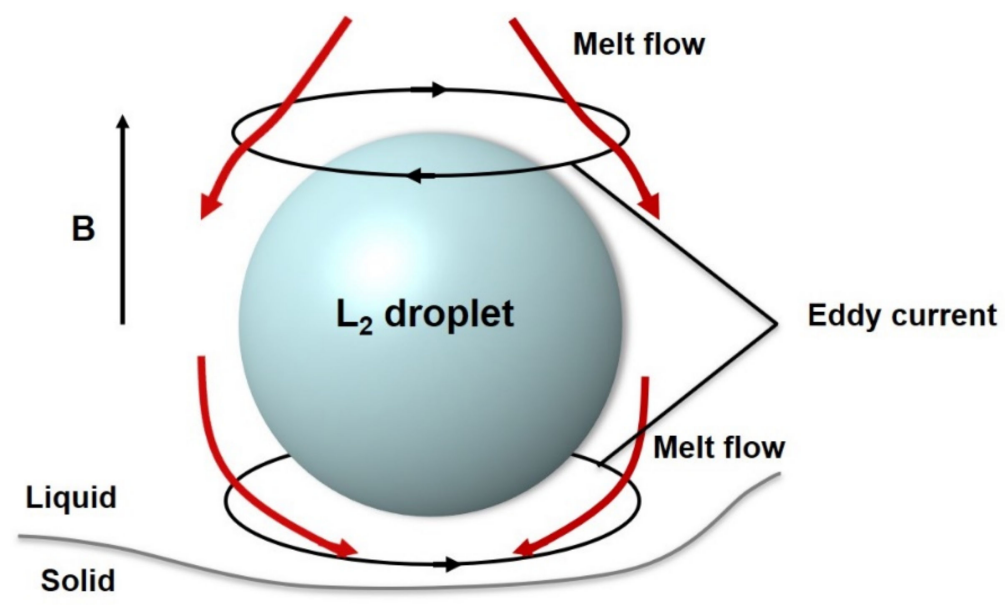

Figure 6. Schematic illustration of the eddy current and Lorentz force of the solidifying front that push the liquid droplets [65].

For the $\mathrm{Ha}$ of different magnitude, the apparent viscosity can be respectively expressed as [66]

$$
\begin{gathered}
\eta_{A}=\eta_{M}\left[1+\frac{H_{a}^{2}}{15}\right], H_{a} \ll 1 \\
\eta_{A}=\frac{1}{3} \eta_{M} /\left[\frac{\operatorname{coth}\left(H_{a}\right)}{H_{a}}-\frac{1}{H_{a}^{2}}\right], H_{a} \approx 1 \\
\eta_{A}=\frac{1}{3} \eta_{M} H_{a}, H_{a} \gg 1
\end{gathered}
$$

It can be seen from the formula that the change of apparent viscosity is directly affected by $\mathrm{Ha}$ number, and the application of HMF can significantly increase the apparent viscosity, thus inhibiting the melt flow. Due to the inhibition of melt flow, the disturbance of the second phase droplets decreases, and their collision and coagulation will be inhibited. If the coalescence is inhibited, the droplets will reach a finer dispersion [67]. Zheng et al. [68] carried out a large number of solidification experiments on $\mathrm{Bi}-\mathrm{Zn}$ immiscible alloy under the HMF above $1 \mathrm{~T}$, and they found that the HMF can reduce the rate of coalescence of minority phase droplets, thereby reducing the macro-segregation of the phase. Wei et al. [69] studied the non-equilibrium solidification of $\mathrm{Cu}-\mathrm{Co}$ immiscible alloy under $\mathrm{HMF}$ and thought that 
the melt flow was only restrained by the Lorentz force perpendicular to the direction of the magnetic field. Once the flow is suppressed, the transport of solute will be affected, and the coagulation in the droplet and sample will be reduced after collision. Ratke et al. [70] studied the solidification process of three Al-base monotectic alloys, namely Al-In, Al-Pb, and $\mathrm{Al}-\mathrm{Bi}$, utilizing $\mathrm{HMF}$, and the experiments showed that HMF can effectively restrain the convection of melting.

\subsection{Microstructure of Immiscible Alloys Modified by HMF \\ 3.5.1. HMF-Controlled Migration and Distribution of Phase}

The migration and distribution of the phase prior to or during solidification is of great significance for the design or control of the solidification microstructure of immiscible alloys [71]. Consequently, the emphasis is often placed on the control of phase migration by HMF. Through the coupling of the solidification process and HMF processing, the migration of the phase in the alloy during solidification process will be changed so that their distribution is controlled and segregation in the final microstructure is restrained [72,73]. In many conditions, especially in engineering materials, segregation has always been undesirable, but it provides benefit guidance for the preparation of functional composite materials [74].

Zhang et al. [68] performed an in situ quenching solidification experiment for BiZn immiscible alloy under HMF. It was found that Stokes and Marangoni motion resulted in segregation of the minority phase when the magnetic field intensity was lower than 17.4 T. However, under the effect of $29 \mathrm{~T} \mathrm{HMF}$, the segregation within the alloy barely existed due to the complete inhibition of Marangoni migration of the minority phase. Moreover, it has been known for a long time that $\mathrm{F}_{\text {TEMF }}$ can significantly inhibit convection in the alloy melt and alter the phase migration behavior during the solidification process, thus obviously inhibiting segregation of the phase in the immiscible alloy and obtaining a more uniform microstructure [75-77]. Zhong et al. [78] studied the effect of $\mathrm{F}_{\mathrm{TEMF}}$ on the mass transfer during solidification of the Zn-6wt.\%Bi immiscible alloys under the action of a weak transverse magnetic field, which changed the segregation behavior of the Bi-rich phase. For the longitudinal macrostructure of alloys solidified without HMF, the segregation degree of the Bi-rich phase in the bottom left side and the bottom right side of the sample was basically the same. With the increase of magnetic flux densities, the Bi-rich particles were pushed from the lower left side to the lower right side by $\mathrm{F}_{\text {TEMF }}$ (see Figure 7).
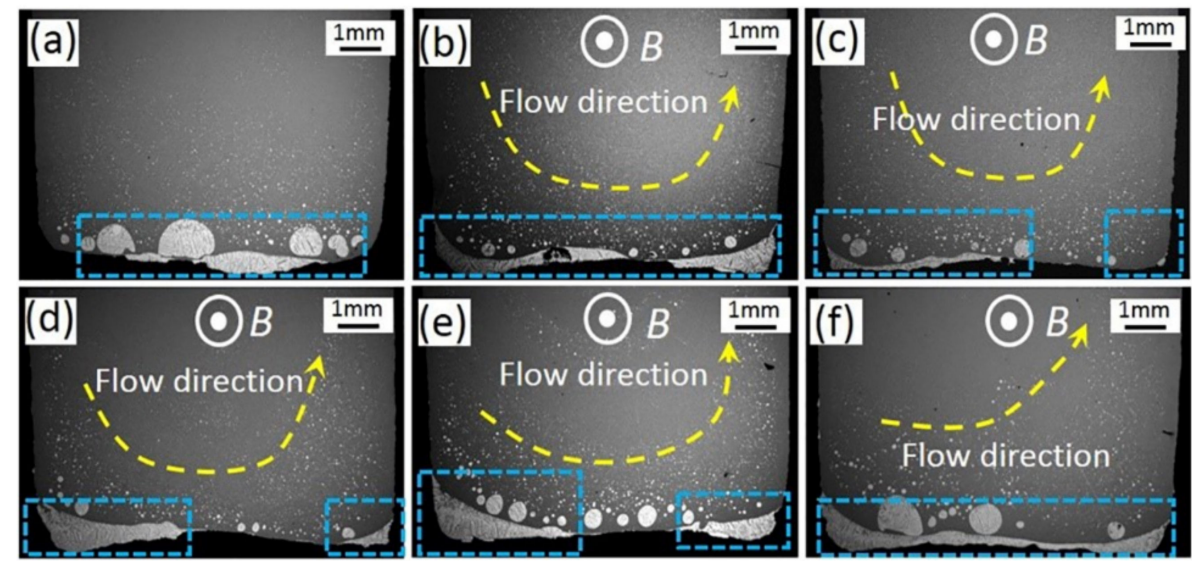

Figure 7. Macrostructure of the longitudinal section of alloys solidified with and without the magnetic field: (a) $0 \mathrm{~T}$; (b) $0.05 \mathrm{~T}$; (c) $0.1 \mathrm{~T}$; (d) $0.22 \mathrm{~T}$; (e) $0.43 \mathrm{~T}$; (f) $1.05 \mathrm{~T}$. The dotted lines indicate the flow direction of liquid $\mathrm{Zn}$-rich phase melt. Blue rectangles indicate the segregated Bi-rich phases at a specific position [78].

Zhao et al. $[18,79,80]$ performed a large number of solidification experiments on $\mathrm{Al}-\mathrm{Pb}$ alloys by applying a magnetic field device, and the modeling and simulation of the system 
were carried out in combination with experiments. The results indicated that the lowintensity magnetic field could only reduce the Marangoni migration velocity and Stokes settlement velocity of minority phase droplet during the liquid-liquid decomposition. It affected the solidification process of immiscible alloy mainly by effectively inhibiting melt convection, which resulted in a nucleation rate of minority phase droplets more uniformly along the radial distribution of the alloy. It is expected that these results will be helpful for researchers to proceed with a deeper study on manufacturing immiscible alloy without any composition segregation by superimposing HMF.

It is well-known that the phase segregation on both macroscopic and microscopic scales will lead to the degradation of properties of alloys in solidification [81,82]. Therefore, the method for controlling the phase distribution on the micro and macro scale in material has always been pursued. Based on the theoretical analysis and observation of the solidification microstructure of alloys, the effect of HMF on the phase distribution has been studied extensively [83]. Zhang et al. [84] studied the size distribution of Co-rich phase particles in the phase-separated $\mathrm{Cu}_{75} \mathrm{Co}_{25}$ alloy under a magnetic field of $4 \mathrm{~T}$. The results showed that the forced convective flow can be restrained effectively via an appropriate magnetic field, and the size distribution of the second phase droplets can be significantly changed (see Figure 8). Shoji et al. [85] investigated the phase distribution in undercooled $\mathrm{Cu}-\mathrm{Co}$ alloy by neutron computed tomography. The three-dimensional image reconstruction showed that when the external magnetic field was relatively weak, a large number of small Co-rich spherical particles were precipitated and uniformly dispersed in the matrix. With the increase of the HMF intensity, these Co-rich particles tended to coagulate and elongate along the direction of the magnetic field, and its number increased. The results demonstrated that the melt convection altered the phase distribution of alloy, which could be controlled via the application of HMF, which can be introduced to commendably manipulate the distribution of the phase that is normally present in immiscible alloys.

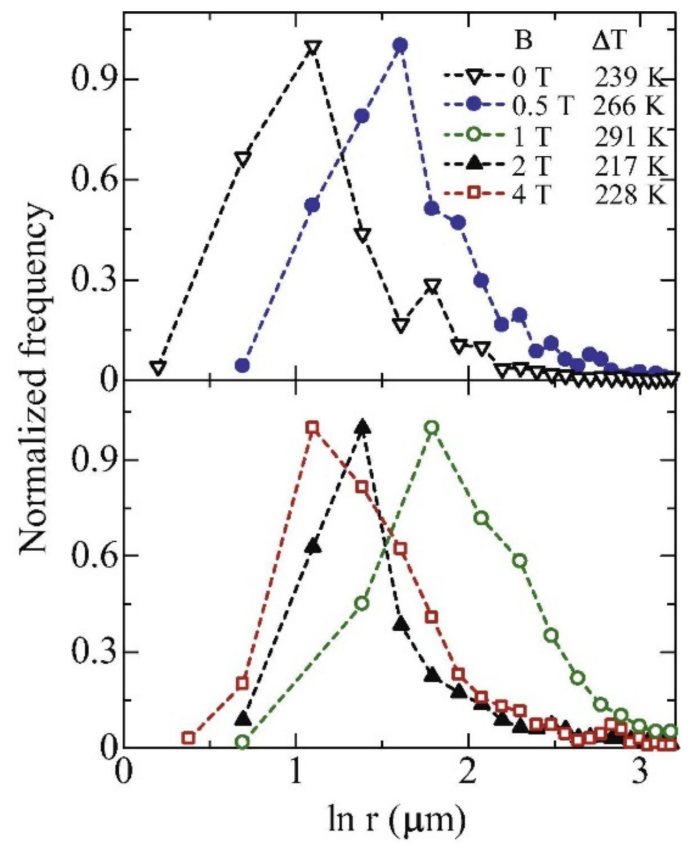

Figure 8. Normalized frequency of particle size distribution of Co-rich particles as a function of particle radius for liquid phase-separate $\mathrm{Cu}_{75} \mathrm{Co}_{25}$ alloys under different undercoolings and magnetic fields [84].

A series of immiscible alloys with unique microstructures were prepared by controlling the distribution of the phase during the solidification process under HMF. Wei et al. [52] analyzed the influence of HMF on the microstructure evolution of undercooled $\mathrm{Cu}-\mathrm{Co}$ alloy. Without the HMF, the initial form of Co-rich phase was spherical. After $10 \mathrm{~T}$ HMF 
was applied, the Co-rich phase was elongated along the direction of HMF owing to the demagnetization energy (see Figure 9b). Nevertheless, in the direction perpendicular to the HMF, the distribution of Co-rich phase was relatively uniform on the matrix (see Figure 9c). Zhang et al. [86] found that an application of $1 \mathrm{~T}$ HMF inhibited the macroscopic segregation of $\mathrm{Cu}-\mathrm{Pb}-\mathrm{La}$ alloy and reduced the size of $\mathrm{Cu}$-rich phase particles, making the microstructure uniformly distributed. Li et al. [87] solidified the immiscible pseudo-binary ( $\mathrm{Fe}-\mathrm{C})-50 \mathrm{mass} \% \mathrm{Cu}$ alloy in $\mathrm{HMF}$ and observed the change of its macro morphologies with the magnetic flux density. When the alloy solidified under the low magnetic flux density, the Fe-rich phase was characterized by a single mass. Under the high magnetic flux density, the Fe-rich phase was separated into two smaller masses, and the distribution distance between the masses increased with increase of magnetic flux density.

To further incorporate the HMF into the phase field model to describe detailed effects on the solidification microstructure, through the combination of numerical simulation and experiment, intensive studies have been carried out to comprehend the role of the HMF. Samanta et al. [88] researched the effects of HMF on the convection damping and macrosegregation inhibition during the solidification process of alloy by numerical simulation. The results demonstrated that the application of HMF to control the thermosolutal convection and eliminate some defects was successful in the solidification process of metallic alloys. Zhang et al. [89] discussed the influence of HMF on the coarsening process of $\mathrm{Cu}-\mathrm{Pb}$ immiscible alloy both by the experiment and simulation. The analysis showed that in the melt without HMF, there was an obvious cyclic flow in the melt, while in the melt with HMF, the flow in most areas was inhibited, and the flow was mainly transferred to the region near the side wall. The HMF resulted in a reduction in the flow velocity of melt, and could also result in a reduction in moving velocity of the $\mathrm{Cu}$-rich droplets.

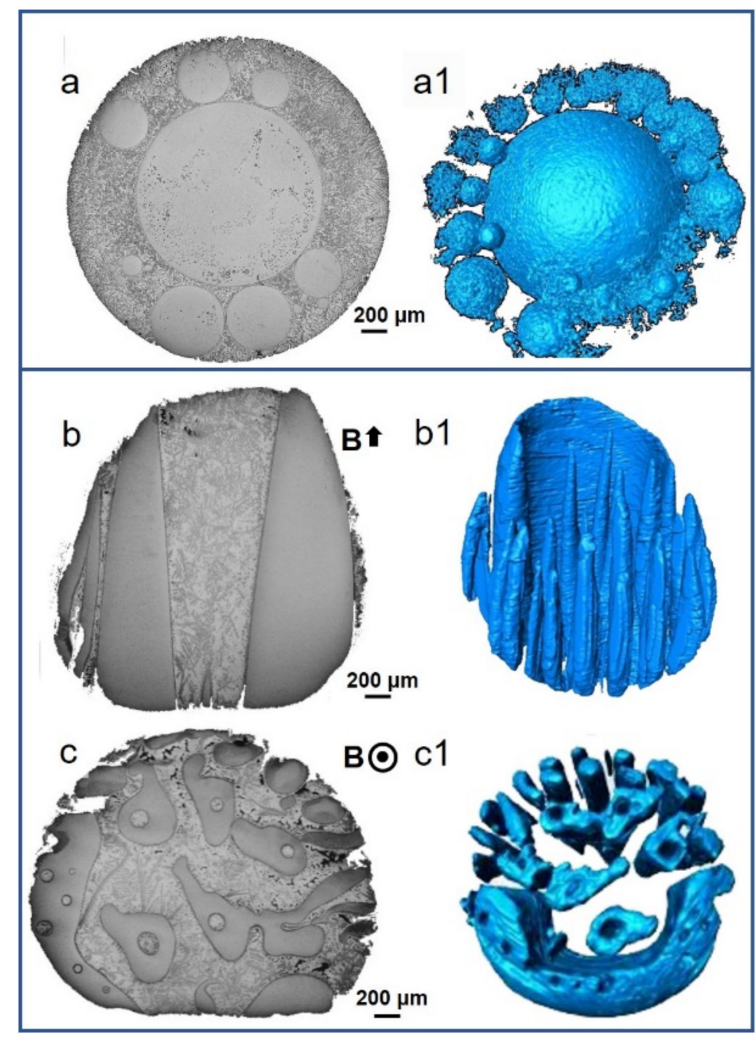

Figure 9. The solidification microstructure of $\mathrm{Cu}_{66.67} \mathrm{Co}_{33.33}$ alloys under different magnetic fields with the undercooling of $260 \mathrm{~K}$ : (a) 0 T, overview optical microscope image; (b) $10 \mathrm{~T}$, an optical micrograph of parallel to the direction of magnetic field; (c) $10 \mathrm{~T}$, an optical micrograph of perpendicular to the direction of magnetic field; a1, b1, c1 3-dimensional microstructure of $(\mathbf{a}-\mathbf{c})$ [52]. 


\subsubsection{Formation of Graded Microstructure Tailored by HMF}

The influence of the gradient magnetic field depends on the physical properties of the element [90]. The application of a gradient magnetic field furnishes another method for controlling the phase distribution of immiscible alloy during the solidification process, which primarily relies on the difference in magnetic susceptibility between the solid phase and liquid matrix. In addition, as for functionally graded materials, its microstructure and chemical composition change continuously and smoothly and are accompanied by a change of free surface depth. Wang et al. [91] chose the Mn-Bi alloy system as a model material, and they observed that the gradient and direction of the applied fields played a crucial role in the aggregation and migration of the ferromagnetic primary Mn-Bi grains in the alloy melt. Under the positive field gradient, the volume of ferromagnetic primary $\mathrm{Mn}-\mathrm{Bi}$ phases decreased along the distance from top to bottom but increased under the negative field gradient.

Zhao et al. [92] explored the effects of a non-uniform magnetic field generated via a superconducting magnet on the solidification behavior of $\mathrm{Cu}_{84} \mathrm{Co}_{16}$ immiscible alloys. The application of inhomogeneous magnetic fields with positive and negative gradients led to Co-rich droplets to segregate at the top and bottom of the sample (see Figure 10), respectively, which indicates that the reversal of a sign of the gradients gives rise to the opposite separation patterns. Due to the gradient distribution of the phase, the solidified microstructure of the alloy presents a continuous change in morphology. Based on this mechanism, the microstructure of immiscible alloy forms a layered microstructural gradient by controlling the distribution of phase in the high-gradient magnetic field. To explore the possibility of simultaneously controlling the particle migration in the solidification process, Liu et al. [93] chose a Bi-11.8 mass\%Mn multiphase alloy system as the experimental material. The alloy solidified at a lower cooling rate under different high-gradient magnetic fields, and it was found that four phases (primary $\mathrm{Mn}-\mathrm{Bi}$, primary $\mathrm{Mn}$, eutectic $\mathrm{Mn}-\mathrm{Bi}$, and eutectic $\mathrm{Bi}$ ) successively precipitated during the solidification process of the alloy. By increasing the magnetic gradient $\mathrm{BdB} / \mathrm{dz}$ to $100 \mathrm{~T}^{2} \mathrm{~m}^{-1}$, a graded microstructure with three layers could be obtained. Nevertheless, when a gradient magnetic field of $\mathrm{BdB} / \mathrm{dz}$ $=300 \mathrm{~T}^{2} \cdot \mathrm{m}^{-1}$ was imposed, the distribution of three layers was completely opposite to that without the magnetic field. Combined with the calculation results, the distribution of primary Bi-Mn and $\mathrm{Mn}$ in the alloy under different gradient magnetic fields could be predicted. The prediction confirmed that the migration of the phase could be simultaneously controlled by imposing high-gradient magnetic fields in the solidification process.
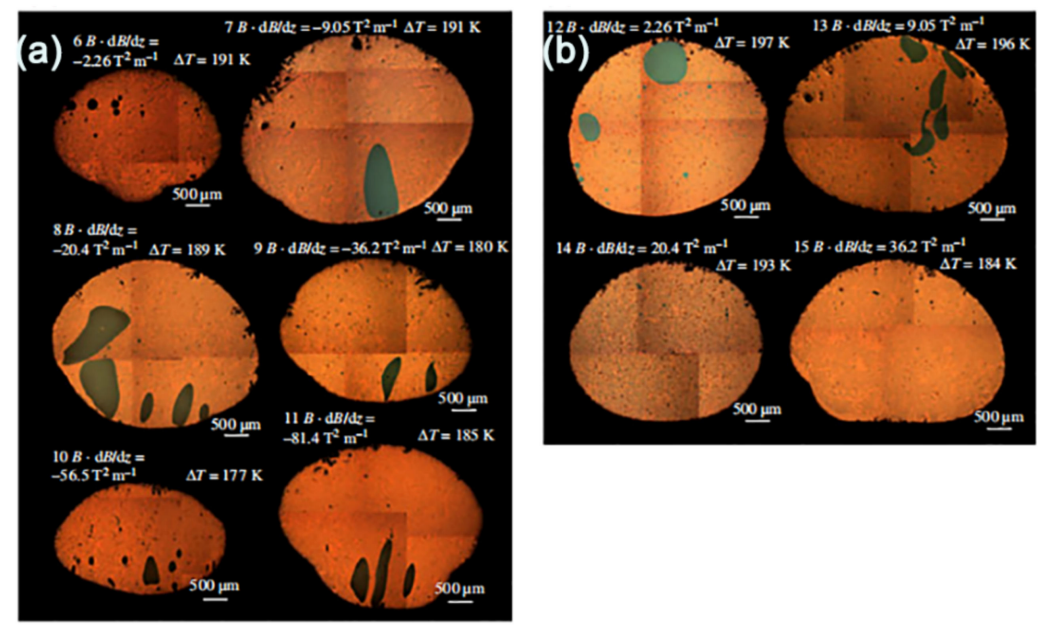

Figure 10. Optical micrographs presenting cross-sectional microstructure of the undercooled and solidified samples under inhomogeneous magnetic fields with (a) negative and (b) positive gradients. All cross-sections were chosen to be parallel to the direction of the magnetic fields. The minor phase with dark contrast is the Co-rich solid solution, and the matrix phase with bright contrast is the $\mathrm{Cu}$-rich solid solution [92]. 
The related research proved the feasibility of preparing the graded microstructure of immiscible alloys under HMF, but the specific position of segregation components accurately could still not be controlled.

\section{Crystal Orientation and Properties of Immiscible Alloys Tuned by HMF \\ 4.1. Effect of HMF on the Crystal Orientation}

Former studies have shown that under the action of HMF, the crystal with an anisotropic magnetic susceptibility will rotate at a certain angle, driven by the magnetic torque, thus obtaining a certain crystal orientation [94-97]. Under the action of the axial HMF, the orientation of solidified Fe-4.5wt\%.Si alloy changed significantly [98]. The magnetic torque created by the anisotropy of the magnetic crystal was applied to the crystal when the $\alpha$-Fe crystal appeared in the melt. Due to the slow cooling rate, the rotation of $\alpha$-Fe crystal was completed before the liquid phase completely solidified. With the increase of magnetic field strength from 0 to $6 \mathrm{~T}$, the $<100>$ crystal orientation of the sample gradually changed to the magnetic field direction, and a strong Goss texture was obtained under $6 \mathrm{~T} \mathrm{HMF}$. Zheng et al. [99] studied the orientation behavior of Bi-5wt.\% $\mathrm{Zn}$ alloy under different HMFs and discovered that when the magnetic flux density increased to $6 \mathrm{~T}$, the c-axes of $\mathrm{Zn}$ crystals were highly oriented along the direction of HMF, and the alloy had the maximum magnetic susceptibility. Furthermore, Li et al. [100] investigated the evolution of microstructures of solidified Al-12wt.\%Ni alloy under $12 \mathrm{~T} \mathrm{HMF}$ and found that the orientation of $\mathrm{Al}_{3} \mathrm{Ni}$ crystals made the planes of $\mathrm{Al}_{3} \mathrm{Ni}$ phases perpendicular to the HMF direction. Meanwhile, Li et al. [101] found the same phenomenon in the directional solidification of Al-Ni alloy under a weak transverse magnetic field.

In addition, if the easy orientation axis of the crystal is the same as the direction of preferred growth, the magnetic field will enhance the growth of the crystal. Zuo et al. [102] found that the HMF can change the morphology and orientation of Fe-rich dendrites in Fe- $49 \% \mathrm{Sn}$ immiscible alloy. After the application of HMF, the primary $\alpha$-Fe dendrites tend to arrange along the parallel direction of the imposed HMF, and this arrangement gradually increases with increases of magnetic induction intensity. It is considered that the magnetic anisotropy energy of the crystal increases due to the action of an HMF, which makes $\alpha$-Fe dendrites have a preferentially oriented growth. Wang et al. [91] characterized the orientation arrangement of $\mathrm{Mn}-\mathrm{Bi}$ alloys under high gradient magnetic field. The Mn-Bi particles strongly gathered on one side of the sample to form a highly aligned microstructure. Due to the magnetic force and magnetic dipole-dipole interactions, the primary $\mathrm{Mn}-\mathrm{Bi}$ phase to be separated from the alloy melted and caused the collision of particles, thereby forming the microstructure with high alignment. During the solidification process of Bi-4.5wt.\%Mn alloy [103], the magnetized Mn-Bi (low temperature phase (LTP)) can be multilayered and oriented by superimposing a 30 T HMF. The different orientations of magnetized LTPS are mainly governed by the force torque, magnetic gradient force, and the attraction of opposite magnetic poles.

\subsection{Effect of HMF on the Magnetic Properties}

Due to the magnetic dipole moment of the material atoms, it is clear that the external magnetic field will have an appreciable impact on the magnetic properties of the material when placed in an external magnetic field. The properties of the material have always been related to their microstructure [104,105]. The technology of solidification under the influence of HMF has great prospects in the preparation of materials with high performance, especially the magnetic properties. Zuo et al. [106] studied magnetic properties of the Fe-49\%Sn immiscible alloy solidified without and with HMF of $10 \mathrm{~T}$. As shown in Figure 11, when the applied HMF is up to $10 \mathrm{~T}$, the magnetization curves obviously change, indicating that the applied HMF during the solidification process of Fe- $49 \% \mathrm{Sn}$ alloy can significantly improve the magnetic properties. The variation of magnetic properties of Fe-Sn alloy is principally due to the aligned microstructure of Fe-Sn alloy ameliorated by the imposition of the HMF to the solidification process. Liu et al. [107] carried out a bulk solidification 
experiment on Fe-1.0wt.\%Si immiscible alloy under the action of 0, 0.3, and $0.6 \mathrm{~T}$ transverse weak magnetic fields. They found that as the magnetic flux density increased, the saturation magnetic induction strength of alloy increased gradually. From a magnetism point of view, the magnetic domain in the matter rotates on the easy magnetic axes toward the direction of magnetic field through the movement of the magnetic domain wall in the magnetization process. This discovery is of great significance because it highlights the effect of HMF on magnetic anisotropy during the solidification process. It opens up a promising path for the preparation of silicon steel materials with magnetic anisotropy and improvement of their magnetic properties.

The intermetallic compound $\mathrm{Mn}-\mathrm{Bi}$ is proposed to be a permanent magnetic material with ferromagnetism at room temperature. Li et al. [108] researched the effect of HMF on the magnetic properties of $\mathrm{Bi}-\mathrm{Mn}-\mathrm{Bi}$ composite materials via directional solidification. The experimental results indicated that the percentage of ferromagnetic Mn-Bi phase will increase during directional solidification under HMF because HMF promotes the phase transition from $\mathrm{Mn} 1.08 \mathrm{Bi}$ to $\mathrm{Mn}-\mathrm{Bi}$, resulting in an increase in the remanence $(\mathrm{Br})$ of the samples prepared under a $10 \mathrm{~T}$ magnetic field. For the Bi-4.4 mass\% Mn alloy [91], the gradient and direction of the applied field play a crucial role in the aggregation and migration of the primary $\mathrm{Mn}-\mathrm{Bi}$ particle in the melt. In the solidification process, the magnetic force drives the ferromagnetic primary Mn-Bi phase towards one side of the alloy where it accumulates, which increases the volume fraction of the alloy by more than $40 \%$. The hysteresis loops of the longitudinal section of specimens demonstrated that the magnetic properties of the solidified samples under the application of HMFs are significantly higher than those under $0 \mathrm{~T}$, and the magnetic properties of the solidified sample under the positive field gradient are significantly lower than that under the negative field gradient. It can provide a novel idea for the preparation of magnetic material with a high-volume fraction and preferential alignment.

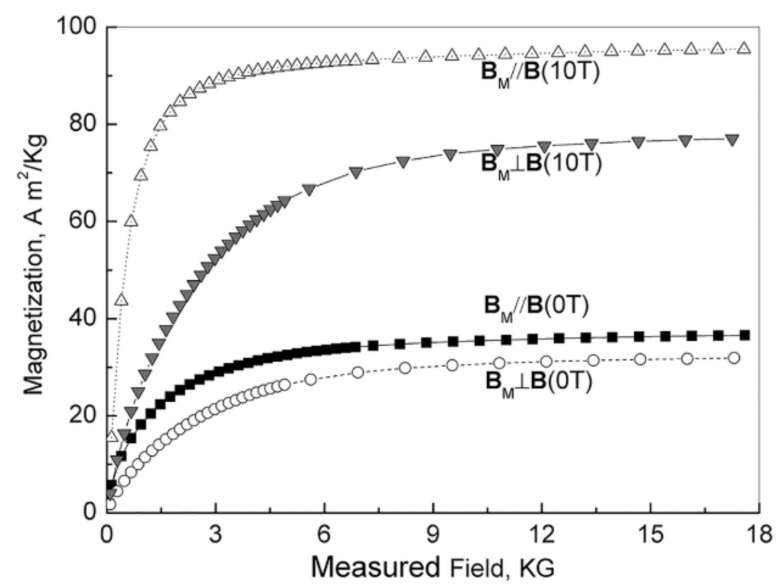

Figure 11. Hysteresis loops of Fe-49\%Sn alloys solidified with the applied magnetic field B of $0 \mathrm{~T}$ and $10 \mathrm{~T}$, where "//" and " $\perp$ " indicate the directions of the magnetic fields for the magnetization measurement (denoted by $B_{M}$ ) parallel and perpendicular to the applied magnetic field B during the solidification process, respectively [106].

Table 1 summarizes the reported HMF influences on the solidification process of immiscible alloys, illustrating that the migration, segregation, and interaction of the minority phase could all be affected by HMF. 
Table 1. Summary of reported HMF influences on the solidification process of immiscible alloy.

\begin{tabular}{|c|c|c|c|}
\hline Immiscible Alloy & Minority Phase & HMF Influences & References \\
\hline $\mathrm{Al}-\mathrm{Pb}$ alloy & $\mathrm{Pb}$-rich phase & Migration damping & {$[79,80]$} \\
\hline Al-In alloy & In-rich phase & Segregation damping, alignment & {$[65]$} \\
\hline Al-Ni alloy & $\mathrm{Al}_{3} \mathrm{Ni}$ phase & Segregation, alignment, rotation & {$[77]$} \\
\hline Al-Bi alloy & Bi-rich phase & Segregation damping & [109] \\
\hline In-Sn alloy & Sn-rich phase & Diffusion damping & {$[58,59]$} \\
\hline $\mathrm{Cu}-\mathrm{Pb}$ alloy & Pb-rich phase & Segregation damping & [64] \\
\hline $\mathrm{Cu}-\mathrm{Co}$ alloy & Co-rich phase & $\begin{array}{l}\text { Magnetization energy, segregation } \\
\text { damping }\end{array}$ & {$[37,84]$} \\
\hline $\mathrm{Bi}-\mathrm{Zn}$ alloy & Bi-rich phase & Segregation damping, alignment & {$[78,99]$} \\
\hline Mn-Bi alloy & Mn-Bi phase & Alignment, segregation & [91] \\
\hline Bi-Mn alloy & Mn crystal & Segregation, interaction, alignment & [93] \\
\hline Fe-Si alloy & $\alpha$-Fe crystal & Orientation, alignment & [98] \\
\hline Fe-Sn alloy & Fe-rich phase & Orientation, alignment & [102] \\
\hline
\end{tabular}

\section{Conclusions and Outlook}

The purpose of this paper is to furnish a deeper understanding and more effective overview of the solidification process of immiscible alloys in the field of HMF processing utilizing HMF targeting the manipulation of the phase migration and improvement of the physical properties. During the solidification process, the HMF primarily produces Lorentz force, $\mathrm{F}_{\mathrm{TEMF}}$, magnetic force, magnetic dipole-dipole interaction, magnetic torque and magnetostatic energy on materials. By coupling these magnetic effects, it is found that the application of HMF is a powerful means to tune the microstructure of immiscible alloy.

It is indispensable to study the microstructure of immiscible alloy to alter its properties. A series of case studies and associated magnetic field effects confirm the possibility that the HMF can be utilized to alter or design the microstructure of material that meet the application requirements of advanced technology. To further expedite the development of immiscible alloys and promote their wide application in engineering, the follow are some outlooks for future work:

At present, simulation of the phase separation process of immiscible alloy mainly calculates the coarsening mechanism of the second phase droplet in the immiscible region. In reality, the solidification speed of immiscible alloys is very fast, and the droplet migration and interaction are very complex, which greatly limits the researchers to obtain the real and reliable evolution path by using the simulation method.

For research of multicomponent immiscible alloy systems, if the solidification process can be controlled by HMF, it will be the key design step to prepare immiscible alloys with core-shell structures with a high melting point phase wrapped by a low melting point phase and controllable structure and size so as to meet the morphology requirements of different types of core-shell immiscible alloys.

Moreover, the industrial scale application of immiscible alloys is still limited. Therefore, the focus of HMF processing may need to further characterize the relationship between the properties (such as corrosion resistance, wear resistance, electrical resistivity, etc.) and the microstructure and focus on expanding the application of immiscible alloys in various fields, which is also expected to play a guiding role in the preparation of other alloys.

Because the electromagnetic processing of materials involves a wide range of fields and the theory is complex, the specific mechanism of the magnetic field on the solidification process of immiscible alloy remains to be further studied. It is believed that in the near future, through continuous efforts, HMF will become a core force controlling the solidification process in material solidification technology. 
Author Contributions: Conceptualization, E.B. and J.W.; methodology, Y.H.; software, C.W.; validation, J.W. and Y.H.; formal analysis, C.W.; investigation, C.W.; resources, J.L.; data curation, C.W.; writing-original draft preparation, C.W.; writing—review and editing, Y.H.; visualization, J.W.; supervision, J.W.; project administration, J.W.; funding acquisition, J.L. All authors have read and agreed to the published version of the manuscript.

Funding: This research was funded by the Natural Science Foundation of China (No.51690163), the fund of the State Key Laboratory of Solidification Processing in NWPU (No. 2019-TS-04), the seed Foundation of Innovation and Creation for Graduate Students in Northwestern Polytechnical University (CX2020076), the Innovation Capability Support Program of Shaanxi.

Acknowledgments: This work was supported by the Natural Science Foundation of China (No.51690163), the fund of the State Key Laboratory of Solidification Processing in NWPU (No. 2019-TS-04), the seed Foundation of Innovation and Creation for Graduate Students in Northwestern Polytechnical University (CX2020076), the Innovation Capability Support Program of Shaanxi (No.2020KJXX-073), and the Fundamental Research Funds for the Central Universities. We acknowledge the support of the LNCMI-CNRS, member of the European Magnetic Field Laboratory (EMFL).

Conflicts of Interest: The authors declare no conflict of interest.

\section{References}

1. Zhao, J.; Ahmed, T.; Jiang, H.; He, J.; Sun, Q. Solidification of Immiscible Alloys: A Review. Acta Metall. Sin. 2017, 30, 1-28. [CrossRef]

2. Uchida, S.; Kimura, T.; Nakamoto, T.; Ozaki, T.; Miki, T.; Takemura, M.; Oka, Y.; Tsubota, R. Microstructures and electrical and mechanical properties of Cu-Cr alloys fabricated by selective laser melting. Mater. Des. 2019, 175, 107815. [CrossRef]

3. Terzieff, P.; Lück, R. Magnetic investigations in liquid Al-In. J. Alloy. Compd. 2003, 360, 205-209. [CrossRef]

4. Wang, J.; Yao, N.; Li, M.; Hu, J.; Chen, J.; Hao, Q.; Wu, K.; Zhou, Y. Electrochemical tuning of the activity and structure of a copper-cobalt micro-nano film on a gold electrode, and its application to the determination of glucose and of Chemical Oxygen Demand. Microchim. Acta 2015, 182, 515-522. [CrossRef] [PubMed]

5. Jia, P.; Li, Y.; Hu, X.; Zhang, J.; Teng, X.; Zhao, D.; Chen, Q.; Zuo, M.; Liu, Q.; Yang, C. Formulation of Al-Bi-Sn immiscible alloys versus the solidification behaviors and structures. J. Mater. Sci. 2019, 54, 4384-4399. [CrossRef]

6. Sun, X.; He, J.; Chen, B.; Zhang, L.; Jiang, H.; Zhao, J.; Hao, H. Microstructure formation and electrical resistivity behavior of rapidly solidified Cu-Fe-Zr immiscible alloys. J. Mater. Sci. Technol. 2020, 44, 201-208. [CrossRef]

7. Raghavan, R.; Harzer, T.P.; Chawla, V.; Djaziri, S.; Philippi, B.; Wehrs, J.; Wheeler, J.M.; Michler, J.; Dehm, G. Comparing small scale plasticity of copper-chromium nanolayered and alloyed thin films at elevated temperatures. Acta Mater. 2015, 93, 175-186. [CrossRef]

8. Ohnuma, I.; Saegusa, T.; Takaku, Y.; Wang, C.P.; Liu, X.J.; Kainuma, R.; Ishida, K. Microstructural Evolution of Alloy Powder for Electronic Materials with Liquid Miscibility Gap. J. Electron. Mater. 2008, 38, 2-9. [CrossRef]

9. He, J.; Zhao, J.; Wang, X.; Gao, L. Microstructure development in finely atomized droplets of copper-iron alloys. Metall. Mater. Trans. A 2005, 36, 2449-2454. [CrossRef]

10. Liu, S.; Jie, J.; Guo, Z.; Yin, G.; Wang, T.; Li, T. Solidification microstructure evolution and its corresponding mechanism of metastable immiscible Cu80Fe20 alloy with different cooling conditions. J. Alloy. Compd. 2018, 742, 99-106. [CrossRef]

11. Jegede, O.E.; Cochrane, R.F.; Mullis, A.M. Metastable monotectic phase separation in Co-Cu alloys. J. Mater. Sci. 2018, 53, 11749-11764. [CrossRef]

12. He, S.; Li, C.; Guo, R.; Xuan, W.; Wang, J.; Ren, Z. Evolution of microsegregation in directionally solidified Al-Cu alloys under steady magnetic field. J. Alloy. Compd. 2019, 800, 41-49. [CrossRef]

13. Li, X.; Lu, Z.; Fautrelle, Y.; Gagnoud, A.; Moreau, R.; Ren, Z. Effect of a weak transverse magnetic field on the microstructure in directionally solidified peritectic alloys. Sci. Rep. 2016, 6, 37872. [CrossRef]

14. Zou, J.; Lu, D.P.; Liu, K.M.; Fu, Q.F.; Zhou, Z. Influences of Alternating Magnetic Fieldson the Growth Behavior and Distribution of the Primary Fe Phasein Cu-14Fe Alloys during the Solidification Process. Metals 2018, 8, 571. [CrossRef]

15. Du, D.; Haley, J.C.; Dong, A.; Fautrelle, Y.; Shu, D.; Zhu, G.; Li, X.; Sun, B.; Lavernia, E.J. Influence of static magnetic field on microstructure and mechanical behavior of selective laser melted AlSi10Mg alloy. Mater. Des. 2019, 181, 107923. [CrossRef]

16. Wang, J.; Li, J.; Kou, H.; Beaugnon, E. Instability Pattern Formation in a Liquid Metal under High Magnetic Fields. Sci. Rep. 2017, 7, 2248. [CrossRef]

17. Zou, Q.; Han, N.; Zhang, Z.; Jie, J.; Xu, F.; An, X. Enhancing Segregation Behavior of Impurity by Electromagnetic Stirring in the Solidification Process of Al-30Si Alloy. Metals 2020, 10, 155. [CrossRef]

18. Jiang, H.; Zhao, J. Solidification of Immiscible Alloys under the Effect of Electric and Magnetic Fields. Acta Metall. Sin. 2018, 31, 1240-1248. [CrossRef] 
19. Sugioka, K.; Inoue, T.; Kitahara, T.; Kurosawa, R.; Kubo, M.; Tsukada, T.; Uchikoshi, M.; Fukuyama, H. Study on the Effect of Melt Convection on Phase Separation Structures in Undercooled CuCo Alloys Using an Electromagnetic Levitator Superimposed with a Static Magnetic Field. Metall. Mater. Trans. B 2014, 45, 1439-1445. [CrossRef]

20. Luo, L.; Ritchie, R.O.; Su, Y.; Wang, B.; Wang, L.; Chen, R.; Guo, J.; Fu, H. Optimizing the microstructures and mechanical properties of Al-Cu-based alloys with large solidification intervals by coupling travelling magnetic fields with sequential solidification. J. Mater. Sci. Technol. 2021, 61, 100-113. [CrossRef]

21. Shen, Z.; Zhou, B.; Zhong, Y.; Zheng, T.; Ren, W.; Lei, Z.; Ren, Z. Revealing influence mechanism of a transverse static magnetic field on the refinement of primary dendrite spacing during directional solidification. J. Cryst. Growth. 2019, 517, 54-58. [CrossRef]

22. Li, Z.; Hou, T.; Wu, G.; Wu, K.; Lin, H. Thermodynamic Analysis for the Magnetic-Field-Induced Precipitation Behaviours in Steels. Metals 2019, 9, 909. [CrossRef]

23. Gillon, P. Uses of intense d.c. magnetic fields in materials processing. Mat. Sci. Eng. A 2000, 287, 146-152. [CrossRef]

24. Sun, Z.H.I.; Guo, M.; Vleugels, J.; van der Biest, O.; Blanpain, B. Strong static magnetic field processing of metallic materials: A review. Curr. Opin. Solid State Mater. Sci. 2012, 16, 254-267. [CrossRef]

25. Wang, J.; Fautrelle, Y.; Ren, Z.; Li, X.; Nguyenthi, H.; Mangelincknoel, N.; Jaoude, G.S.A.; Zhong, Y.; Kaldre, I.; Bojarevics, A. Thermoelectric magnetic force acting on the solid during directional solidification under a static magnetic field. Appl. Phys. Lett. 2012, 101, 251904. [CrossRef]

26. Liu, T.; Wang, Q.; Zhang, H.; Lou, C.; Nakajima, K.; He, J. Effects of high magnetic fields on solidification microstructure of Al-Si alloys. J. Mater. Sci. 2011, 46, 1628-1634. [CrossRef]

27. Liu, T.; Wang, Q.; Yuan, Y.; Wang, K.; Li, G. High-gradient magnetic field-controlled migration of solutes and particles and their effects on solidification microstructure: A review. Chin. Phys. B 2018, 27, 118103. [CrossRef]

28. Liu, T.; Wang, Q.; Zhang, H.; Wang, K.; Pang, X.; He, J. Effects of high magnetic fields on the microstructures and grain boundaries in binary Al-Li alloy. J. Alloy. Compd. 2009, 469, 258-263. [CrossRef]

29. Fautrelle, Y.; Nguyenthi, H.; Jaoude, G.S.A.; Reinhart, G.; Mangelincknoel, N.; Kaldre, I. Thermoelectric magnetic flows in melt during directional solidification. Appl. Phys. Lett. 2014, 104, 121916. [CrossRef]

30. Zheng, T.; Zhou, B.; Zhong, Y.; Wang, J.; Shuai, S.; Ren, Z.; Debray, F.; Beaugnon, E. Solute trapping in Al-Cu alloys caused by a 29 Tesla super high static magnetic field. Sci. Rep. 2019, 9, 1-9. [CrossRef]

31. Li, X.; Fautrelle, Y.; Gagnoud, A.; Du, D.; Wang, J.; Ren, Z.; Nguyen-Thi, H.; Mangelinck-Noel, N. Effect of a weak transverse magnetic field on solidification structure during directional solidification. Acta Mater. 2014, 64, 367-381. [CrossRef]

32. Dong, M.; Liu, T.; Liao, J.; Xiao, Y.; Yuan, Y.; Wang, Q. In situ preparation of symmetrically graded microstructures by solidification in high-gradient magnetic field after melt and partial-melt processes. J. Alloy. Compd. 2016, 689, 1020-1027. [CrossRef]

33. Kaban, I.; Köhler, M.; Ratke, L.; Nowak, R.; Sobczak, N.; Mattern, N.; Eckert, J.; Greer, A.L.; Sohn, S.W.; Kim, D.H. Phase separation in monotectic alloys as a route for liquid state fabrication of composite materials. J. Mater. Sci. 2012, 47, 8360-8366. [CrossRef]

34. Zhao, J.; Jiang, H.; Sun, Q.; Li, W.; He, J. Progress of Research on Solidification Process and Microstructure Control of Immiscible Alloys. Mater. China 2017, 36, 252-261. [CrossRef]

35. Mullis, A.M.; Jegede, O.E.; Bigg, T.D.; Cochrane, R.F. Dynamics of Core-Shell Particle Formation in Drop-Tube Processed Metastable Monotectic Alloys. Acta Mater. 2020, 188, 591-598. [CrossRef]

36. Liu, S.; Jie, J.; Dong, B.; Guo, Z.; Wang, T.; Li, T. Novel insight into evolution mechanism of second liquid-liquid phase separation in metastable immiscible Cu-Fe alloy. Mater. Des. 2018, 156, 71-81. [CrossRef]

37. Wei, C.; Wang, J.; He, Y.; Yan, Y.; Gao, J.; Li, J.; Beaugnon, E. Liquid-liquid phase separation in immiscible Cu-Co alloy. Mater. Lett. 2020, 268, 127585. [CrossRef]

38. Tang, H.; Wrobel, L.C. Modelling the interfacial flow of two immiscible liquids in mixing processes. Int. J. Eng. Sci. 2005, 43, 1234-1256. [CrossRef]

39. Shi, R.P.; Wang, C.P.; Wheeler, D.; Liu, X.J.; Wang, Y. Formation mechanisms of self-organized core/shell and core/shell/corona microstructures in liquid droplets of immiscible alloys. Acta Mater. 2013, 61, 1229-1243. [CrossRef]

40. Wang, C.; Liu, X.; Shi, R.; Shen, C.; Wang, Y.; Ohnuma, I.; Kainuma, R.; Ishida, K. Design and formation mechanism of self-organized core/shell structure composite powder in immiscible liquid system. Appl. Phys. Lett. 2007, 91, 141904. [CrossRef]

41. Shi, R.; Wang, Y.; Wang, C.; Liu, X. Self-organization of core-shell and core-shell-corona structures in small liquid droplets. Appl. Phys. Lett. 2011, 98, 204106. [CrossRef]

42. Wang, J.; Li, J.; Hu, R.; Kou, H.; Beaugnon, E. Anomalous magnetism and normal field instability in supercooled liquid cobalt. Appl. Phys. Lett. 2014, 105, 144101. [CrossRef]

43. Ikezoe, Y.; Hirota, N.; Nakagawa, J.; Kitazawa, K. Making water levitate. Nature 1998, 393, 749-750. [CrossRef]

44. Martin, J.E.; Venturini, E.L.; Odinek, J.; Anderson, R.A. Anisotropic magnetism in field-structured composites. Phys. Rev. E 2000, 61, 2818-2830. [CrossRef]

45. He, F.Y.; Li, J.; Li, L.; Wang, J.; Yildiz, E.; Beaugnon, E. Magnetic-field-induced chain-like assemblies of the primary phase during non-equilibrium solidification of a Co-B eutectic alloy: Experiments and modeling. J. Alloy. Compd. 2020, 815, 152446. [CrossRef]

46. Sugiyama, T.; Tahashi, M.; Sassa, K.; Asai, S. The Control of Crystal Orientation in Non-magnetic Metals by Imposition of a High Magnetic Field. ISIJ Int. 2003, 43, 855-861. [CrossRef]

47. Sun, Z.H.I.; Guo, M.; Vleugels, J.; van der Biest, O.; Blanpain, B. Processing of non-ferromagnetic materials in strong static magnetic field. Curr. Opin. Solid State Mater. Sci. 2013, 17, 193-201. [CrossRef] 
48. Ren, Z. Progress in Research of Solidification of Metals under a Strong Magnetic Field. Mater. China 2010, 29, 40-49. [CrossRef]

49. Wang, J.; He, Y.; Li, J.; Li, C.; Kou, H.; Zhang, P.; Beaugnon, E. Nucleation of supercooled Co melts under a high magnetic field. Mater. Chem. Phys. 2019, 225, 133-136. [CrossRef]

50. Wang, J.; He, Y.; Li, J.; Kou, H.; Beaugnon, E. Strong magnetic field effect on the nucleation of a highly undercooled Co-Sn melt. Sci. Rep. 2017, 7, 4958. [CrossRef] [PubMed]

51. Liu, T.; Wang, Q.; Liu, F.; Li, G.; He, J. Nucleation behavior of bulk Ni-Cu alloy and pure Sb in High magnetic fields. J. Cryst. Growth. 2011, 321, 167-170. [CrossRef]

52. Wei, C.; Wang, J.; He, Y.; Li, J.; Beaugnon, E. Influence of high magnetic field on the liquid-liquid phase separation behavior of an undercooled Cu-Co immiscible alloy. J. Alloy. Compd. 2020, 842, 155502. [CrossRef]

53. Bian, X.; Zhao, X.; Wu, Y.; Guo, K. Effect of magnetic field on binodal temperature in immiscible alloys. J. Appl. Phys. 2013, 114, 193503. [CrossRef]

54. Wang, Q.; Li, D.; Wang, K.; Wang, Z.; He, J. Effects of high uniform magnetic fields on diffusion behavior at the Cu/Al solid/liquid interface. Scr. Mater. 2007, 56, 485-488. [CrossRef]

55. Li, D.; Wang, Q.; Liu, T.; Li, G.; He, J. Growth of diffusion layers at liquid Al-solid Cu interface under uniform and gradient high magnetic field conditions. Mater. Chem. Phys. 2009, 117, 504-510. [CrossRef]

56. Li, D.; Wang, Q.; Li, G.; Lv, X.; Nakajima, K.; He, J. Diffusion layer growth at Zn/Cu interface under uniform and gradient high magnetic fields. Mat. Sci. Eng. A 2008, 495, 244-248. [CrossRef]

57. Botton, V.; Lehmann, P.; Bolcato, R.; Moreau, R. Measurement of solute diffusivities. Part III. From solutal convection dominated transport to quasi-diffusive transport. Int. J. Heat Mass Transf. 2004, 47, 2457-2467. [CrossRef]

58. Li, D.; Wang, Q.; Wang, K.; Wu, C.; Li, G.; He, J. Diffusion Behavior and Interfacial Reaction of Heterogeneous Metal Systems Controlled by High Magnetic Fields. Mater. Sci. Forum 2012, 706-709, 2910-2915. [CrossRef]

59. Mathiak, G.; Frohberg, G. Interdiffusion and Convection in High Magnetic Fields. Cryst. Res. Technol. 1999, 34, 181-188. [CrossRef]

60. Miyake, T.; Inatomi, Y.; Kuribayashi, K. Measurement of Diffusion Coefficient in Liquid Metal under Static Magnetic Field. Jpn. J. Appl. Phys. 2002, 41, 811. [CrossRef]

61. Li, D.; Wang, Q.; Li, G.; Liu, T.; He, J. High magnetic field controlled interdiffusion behavior at Bi-Bi0.4Sb0.6 liquid/solid interface. J. Mater. Sci. 2009, 44, 1918-1922. [CrossRef]

62. Wang, J.; Zhong, Y.; Fautrelle, Y.; Zheng, T.; Li, F.; Ren, Z.; Debray, F. Influence of the static high magnetic field on the liquid-liquid phase separation during solidifying the hyper-monotectic alloys. Appl. Phys. A 2013, 112, 1027-1031. [CrossRef]

63. Wu, Y.; Wang, W.L.; Chang, J.; Wei, B. Evolution kinetics of microgravity facilitated spherical macrosegregation within immiscible alloys. J. Alloy. Compd. 2018, 763, 808-814. [CrossRef]

64. Wang, E.; Zhang, L.; Zuo, X.; He, J. Morphology of the Cu-rich Phase in Cu-Pb Hypermonotectic Alloys under an Intense Magnetic Field. Steel Res. Int. 2007, 78, 386-390. [CrossRef]

65. Yasuda, H.; Ohnaka, I.; Fujimoto, S.; Takezawa, N.; Tsuchiyama, A.; Nakano, T.; Uesugi, K. Fabrication of aligned pores in aluminum by electrochemical dissolution of monotectic alloys solidified under a magnetic field. Scr. Mater. 2006, 54, 527-532. [CrossRef]

66. Polovin, R.V.; Demutškiü, V.P. Fundamentals of Magnetohydrodynamics; Consultants Bureau: New York, NY, USA, 1990.

67. Yasuda, H.; Ohnaka, I.; Kawakami, O.; Ueno, K.; Kishio, K. Effect of Magnetic Field on Solidification in Cu-Pb Monotectic Alloys. ISIJ Int. 2007, 43, 942-949. [CrossRef]

68. Zheng, T.; Zhong, Y.; Lei, Z.; Ren, W.; Ren, Z.; Debray, F.; Beaugnon, E.; Fautrelle, Y. Effects of high static magnetic field on distribution of solid particles in BiZn immiscible alloys with metastable miscibility gap. J. Alloy. Compd. 2015, 623, 36-41. [CrossRef]

69. Wei, C.; Wang, J.; He, Y.; Kou, H.; Li, J. The effect of high magnetic field on the microstructure evolution of a Cu-Co alloy during non-equilibrium solidification. J. Cryst. Growth. 2019, 515, 78-82. [CrossRef]

70. Ratke, L.; Muller, A.; Seifert, M.; Kapserovich, G. Monotectic Alloys and their Growth Morphologies. Mater. Sci. Forum 2010, 649, 137-142. [CrossRef]

71. Lu, W.; Hu, Q.; Zhang, W.; Li, J. Dynamic behaviors of minor droplets and the role of bubbles in phase-separating AlBi immiscible alloy. J. Mol. Liq. 2020, 320, 114478. [CrossRef]

72. Stelian, C.; Delannoy, Y.; Fautrelle, Y.; Duffar, T. Solute segregation in directional solidification of GaInSb concentrated alloys under alternating magnetic fields. J. Cryst. Growth 2004, 266, 207-215. [CrossRef]

73. Xiao, Y.; Liu, T.; Tong, Y.; Dong, M.; Li, J.; Wang, J.; Wang, Q. Microstructure evolution of peritectic Al-18 at.\% Ni alloy directionally solidified in high magnetic fields. J. Mater. Sci. Technol. 2021, 76, 51-59. [CrossRef]

74. Suresh, S. Graded Materials for Resistance to Contact Deformation and Damage. Science 2001, 292, 2447-2451. [CrossRef]

75. Li, X.; Fautrelle, Y.; Zaidat, K.; Gagnoud, A.; Ren, Z.; Moreau, R.; Zhang, Y.; Esling, C. Columnar-to-equiaxed transitions in al-based alloys during directional solidification under a high magnetic field. J. Cryst. Growth. 2010, 312, 267-272. [CrossRef]

76. Lei, L.; Zhang, Y.; Esling, C.; Zhao, Z.; Zuo, Y.; Zhang, H.; Cui, J. Formation of feathery grains with the application of a static magnetic field during direct chill casting of Al-9.8wt\%Zn alloy. J. Mater. Sci. 2009, 44, 1063-1068. [CrossRef]

77. Wang, C.; Wang, Q.; Wang, Z.; Li, H.; Nakajima, K.; He, J. Phase alignment and crystal orientation of Al3Ni in Al-Ni alloy by imposition of a uniform high magnetic field. J. Cryst. Growth. 2008, 310, 1256-1263. [CrossRef] 
78. Zhong, Y.; Zheng, T.; Dong, L.; Zhou, B.; Ren, W.; Wang, J.; Ren, Z.; Debray, F.; Beaugnon, E.; Wang, H.; et al. Controlling droplet distribution using thermoelectric magnetic forces during bulk solidification processing of a Zn-6wt.\%Bi immiscible alloy. Mater. Des. 2016, 100, 168-174. [CrossRef]

79. Li, H.; Zhao, J. Directional solidification of an Al-Pb alloy in a static magnetic field. Comput. Mater. Sci. 2009, 46, 1069-1075. [CrossRef]

80. Zhao, J.Z.; Li, H.; Wang, Q.; Zhao, L.; He, J. Rapid directional solidification of Al-Pb alloy under a static magnetic field. Acta Metall. Sin. 2009, 45, 1344-1348. [CrossRef]

81. Luo, L.; Luo, L.; Su, Y.; Su, L.; Wang, L.; Guo, J.; Fu, H. Optimizing microstructure, shrinkage defects and mechanical performance of ZL205A alloys via coupling travelling magnetic fields with unidirectional solidification. J. Mater. Sci. Technol. 2021, 74, 246-258 [CrossRef]

82. Li, Z.; Samuel, A.M.; Samuel, F.H.; Ravindran, C.; Valtierra, S. Effect of alloying elements on the segregation and dissolution of CuAl2 phase in Al-Si-Cu 319 alloys. J. Mater. Sci. 2003, 38, 1203-1218. [CrossRef]

83. Wang, Q.; Liu, T.; Wang, K.; Gao, P.; Liu, Y.; He, J. Progress on High Magnetic Field-Controlled Transport Phenomena and Their Effects on Solidification Microstructure. ISIJ Int. 2014, 54, 516-525. [CrossRef]

84. Zhang, Y.; Gao, J.; Yasuda, H.; Kolbe, M.; Wilde, G. Particle size distribution and composition in phase-separated Cu75Co25 alloys under various magnetic fields. Scr. Mater. 2014, 82, 5-8. [CrossRef]

85. Shoji, E.; Isogai, S.; Suzuki, R.; Kubo, M.; Tsukada, T.; Kai, T.; Shinohara, T.; Matsumoto, Y.; Fukuyama, H. Neutron computed tomography of phase separation structures in solidified $\mathrm{CuCo}$ alloys and investigation of relationship between the structures and melt convection during solidification. Scr. Mater. 2020, 175, 29-32. [CrossRef]

86. Zhang, L.; Wang, E.G.; Zuo, X.W.; He, J.C. Effect of Magnetic Field on Liquid-liquid Separation of Cu-Pb-La Hypermonotectic Alloy. Rare Met. Mater. Eng. 2015, 44, 344-348.

87. Li, M.; Tamura, T. Influence of static magnetic field intensity on the separation and migration of Fe-rich bulks in an immiscible (Fe-C)-Cu alloy. Philos. Mag. 2019, 99, 2221-2235. [CrossRef]

88. Samanta, D.; Zabaras, N. Control of macrosegregation during the solidification of alloys using magnetic fields. Int. J. Heat Mass Tran. 2006, 49, 4850-4866. [CrossRef]

89. Zhang, L.; Man, T.; Huang, M.; Gao, J.; Zuo, X.; Wang, E. Numerical Simulation of Droplets Behavior of Cu-Pb Immiscible Alloys Solidifying under Magnetic Field. Materials 2017, 10, 1005. [CrossRef]

90. Hu, S.; Hou, L.; Wang, K.; Liao, Z.; Fautrelle, Y.; Li, W.; Li, X. Formation mechanism of gradient structure of aluminum matrix composite under static magnetic field during directional solidification. J. Mater. Res. Technol. 2020, 9, 4459-4468. [CrossRef]

91. Wang, Q.; Lou, C.; Liu, T.; Wei, N.; Wang, C.; He, J. Fabrication of MnBi/Bi composite using dilute master alloy solidification under high magnetic field gradients. J. Phys. D 2009, 42, 025001. [CrossRef]

92. Zhao, D.; Gao, J. Liquid phase separation in undercooled Cu-Co alloys under the influence of static magnetic fields. Philos. R. Soc. A. 2019, 377, 20180207. [CrossRef]

93. Liu, T.; Wang, Q.; Wang, C.; Liu, Z.; Yuan, Y.; He, J. In-Situ Fabrication of Bi/BiMn-BiMn-Mn Graded Materials by High Magnetic Field Gradients. ISIJ Int. 2010, 50, 1947-1949. [CrossRef]

94. Liu, T.; Wang, Q.; Gao, A.; Zhang, C.; Li, D.; He, J. Crystal orientation and grain alignment in a hypoeutectic Mn-Sb alloy under high magnetic field conditions. J. Alloy. Compd. 2009, 481, 755-760. [CrossRef]

95. Sun, Z.; Guo, X.; Guo, M.; Vleugels, J.; der Biest, O.V.; Blanpain, B. Alignment of weakly magnetic metals during solidification in a strong magnetic field. J. Alloy. Compd. 2013, 551, 568-577. [CrossRef]

96. De Rango, P.; Lees, M.R.; Lejay, P.; Sulpice, A.; Tournier, R.; Ingold, M.; Germi, P.; Pernet, M. Texturing of magnetic materials at high temperature by solidification in a magnetic field. Nature 1991, 349, 770-772. [CrossRef]

97. Liu, T.; Wang, Q.; Zhang, C.; Gao, A.; Li, D.; He, J. Formation of chainlike structures in an Mn-89.7 wt $\%$ Sb alloy during isothermal annealing process in the semisolid state in a high magnetic field. J. Mater. Res. 2009, 24, 2321-2330. [CrossRef]

98. Liu, C.; Zhong, Y.; Shen, Z.; Zheng, T.; Dong, L.; Ren, W.; Lei, Z.; Ren, Z. Effect of an axial high static magnetic field on the crystal orientation and magnetic property of Fe-4.5 wt\% Si alloy during bulk solidification. Mater. Lett. 2019, 247, 189-192. [CrossRef]

99. Zheng, T.; Zhong, Y.; Lei, Z.; Ren, W.; Ren, Z.; Wang, H.; Wang, Q.; Debray, F.; Beaugnon, E.; Fautrelle, Y. Effects of high static magnetic field on crystal orientation and magnetic property of Bi-5wt.\% Zn alloys. Mater. Lett. 2015, 140, 68-70. [CrossRef]

100. Li, X.; Fautrelle, Y.; Ren, Z. Effect of a high magnetic field on the microstructure in directionally solidified Al-12 wt $\% \mathrm{Ni}$ alloy. J. Cryst. Growth. 2007, 306, 187-194. [CrossRef]

101. Li, H.; Fautrelle, Y.; Hou, L.; Du, D.; Zhang, Y.; Ren, Z.; Lu, X.; Moreau, R.; Li, X. Effect of a weak transverse magnetic field on the morphology and orientation of directionally solidified Al-Ni alloys. J. Cryst. Growth. 2016, 436, 68-75. [CrossRef]

102. Zuo, X.; Wang, E.; Han, H.; Zhang, L.; He, J. Microstructures and magnetic properties of Fe-49\%Sn monotectic alloys solidified under a high magnetic field. Acta Metall. Sin. 2008, 44, 1219-1223.

103. Zheng, T.; Zhong, Y.; Dong, L.; Zhou, B.; Ren, Z.; Debray, F.; Beaugnon, E. Orientation of Magnetized MnBi in a Strong Static Magnetic Field. Metall. Mater. Trans. A 2018, 49, 1981-1985. [CrossRef]

104. Rehman, S.U.; Wei, C.; Huang, Q.; Jiang, Q.; Haq, A.u.; Wang, J.; Zhong, Z. Tailoring the microstructure, magnetic properties and interaction mechanisms of Alnico-Ta alloys by magnetic field treatment. J. Alloy. Compd. 2021, 857, 157586. [CrossRef] 
105. Xiang, Z.; Zhang, L.; Xin, Y.; An, B.; Niu, R.; Mardani, M.; Siegrist, T.; Lu, J.; Goddard, R.E.; Man, T.; et al. Ultrafine microstructure and hardness in Fe-Cr-Co alloy induced by spinodal decomposition under magnetic field. Mater. Des. 2021, $199,109383$. [CrossRef]

106. Zuo, X.; Wang, E.; Han, H.; Zhang, L.; He, J. Magnetic properties of Fe-49\%Sn monotectic alloys solidified under a high magnetic field. J. Alloy. Compd. 2010, 492, 621-624. [CrossRef]

107. Liu, C.; Zhong, Y.; Shen, Z.; Dong, L.; Zheng, T.; Ren, W.; Lei, Z.; Ren, Z. Effect of a transverse weak magnetic field on the texture evolution and magnetic property of Fe-1.0 wt.\% Si alloy during bulk solidification. Mater. Res. Express 2019, 6, 066105. [CrossRef]

108. Li, X.; Ren, Z.; Cao, G.; Fautrelle, Y.; Esling, C. Structure, growth characteristic and magnetic properties in directionally solidified Bi-MnBi composite under strong magnetic field. Acta Mater. 2011, 59, 6297-6307. [CrossRef]

109. Zhang, L.; Wang, E.; Wang, H.; Kang, Z.; He, J. Influence of static horizontal magnetic field on Bi-rich phase transition and distribution in Al-Bi monotectic alloy. Chin. J. Rare Met. 2010, 34, 791-796. [CrossRef] 